\title{
INTEGRAÇÃO METODOLÓGICA ENTRE GRUPO DE DISCUSSÃO E ANÁLISE SOCIOLÓGICA DO DISCURSO: UM CASO EXEMPLIFICADOR SOBRE O DISCURSO FEMININO ACERCA DO CONSUMO DA BELEZA ${ }^{1}$
}

\author{
Christiane Kleinübing Godoi ${ }^{2}$ \\ Adriano Silveira Mastella ${ }^{3}$ \\ Antônio Giovanni Figlioulo Uchôa ${ }^{4}$
}

http://dx.doi.org/10.1590/1413-2311.180.69478

\section{RESUMO}

As temáticas e problemas do cotidiano organizacional vêm exigindo práticas metodológicas avançadas originárias e construídas no interior da sociologia. Este artigo discute e demonstra a utilização, de forma integrada, de práticas metodológicas originárias da Tradição Espanhola de Pesquisa Social Qualitativa e, que nos Estudos Organizacionais brasileiros, já tem seu espaço desde meados do ano 2000 - especificamente a Análise Sociológica do Discurso (ASD) e, sua principal técnica coleta correlata - o Grupo de Discussão (GD). Tais metodologias já são bastante teorizadas e inclusive praticadas em nosso campo, porém ainda não haviam sido aplicadas de forma associada nos EORs brasileiros. Para contribuir para a possibilidade de ampliação da utilização das metodologias e auxiliar a prática dos pesquisadores interessados, este artigo tem como objetivo principal apresentar os principais procedimentos - abstraídos do interior de um "caso exemplar" -, ou seja, revelar a forma como se manifestaram a aplicação das metodologias de Grupo de Discurso, cujo "discurso grupal" foi analisado pelos procedimentos e módulos da Análise Sociológica do Discurso. O “caso exemplar" propriamente dito versa sobre o consumo feminino acerca do consumo da beleza e foram conduzidos seis GDs. O delineamento, participantes, teorização do estudo em

\footnotetext{
${ }^{1}$ Submetido em 18/11/2016, aprovado em 12//08/2017.

${ }^{2}$ Universidade do Vale do Itajaí (Brasil) - chriskg@univali.br

${ }^{3}$ Instituto Federal Catarinense (Brasil) - asmastella@yahoo.com.br

${ }^{4}$ Centro Universitário do Norte (Brasil) - uchoag@yahoo.com.br
} 
si são brevemente aprofundados no capítulo introdutório apenas a título de contextualização. O objetivo, portanto, deste trabalho metodológico redigido sob a forma de "caso exemplar" reside em contribuir principalmente para a visualização gráfica dos procedimentos em um estudo empírico que utilize tais metodologias de forma integrada. Os dois primeiros capítulos introduzem o leitor no universo das metodologias de GD e ASD, sua historicidade,

influências epistêmicas, conceitos, o papel do pesquisador, dentre outros elementos. Ao final, emerge o exemplo - sob o comando de um quadro-síntese norteador da construção e interpretação de Representações Gráficas (topográfica) acerca cada procedimento modular.

Palavras-chave: Análise Sociológica do Discurso. Grupo de Discussão. Análise Qualitativa. Consumo de Beleza.

\title{
METHODOLOGICAL INTEGRATION BETWEEN GROUP OF DISCUSSION AND SOCIOLOGICAL DISCOURSE ANALYSIS: AN EXEMPLARY CASE OF FEMININE DISCOURSE ABOUT BEAUTY CONSUMPTION.
}

\begin{abstract}
The thematic and problems of organizational everyday life have demanded advanced methodological practices originating and built within sociology. This article discusses and demonstrates the integrated use of methodological practices originating from the Spanish Tradition of Qualitative Social Research and that in the Brazilian Organizational Studies has already had its space since the middle of the year 2000 - specifically the Sociological Discourse Analysis (SDA) and, its main collection technique - the Discussion Group (DG). Such methodologies are already well-theorized and even practiced in our field but have not yet been applied in an associated way in Brazilian EORs. In order to contribute to the possibility of expanding the use of methodologies and to assist the practice of interested researchers, this article has as main objective to present the main procedures - abstracted from the interior of an "exemplary case" - that is, to reveal how they manifested themselves the application of Discourse Group methodologies, whose "group discourse" was analyzed by the procedures and modules of the Sociological Discourse Analysis. The "exemplary case" itself refers to the female consumption of the consumption of beauty and six GDs were conducted. Designs, participants, theorization of the study itself are briefly outlined in the introductory chapter only as a contextualization. The objective, therefore, of this
\end{abstract}


methodological work written as an "exemplary case" is to contribute mainly to the graphic visualization of the procedures in an empirical study that uses such methodologies in an integrated way. The first two chapters introduce the reader in the universe of GD and ASD methodologies, their historicity, epistemic influences, concepts, the role of the researcher, among other elements. At the end, the example emerges - under the command of a guiding summary of the construction and interpretation of Graphic Representations (topographic) about each modular procedure.

Key-words: Sociological Discourse Analysis. Discussion Group. Qualitative Analysis. Beauty Consumption.

\section{INTEGRACIÓN METODOLÓGICA ENTRE GRUPO DE DISCUSIÓN Y ANÁLISIS SOCIOLÓGICA DEL DISCURSO: UN CASO EJEMPLIFICADOR SOBRE EL DISCURSO FEMENINO ACERCA DEL CONSUMO DE LA BELLEZA}

\section{RESUMEN}

Las temáticas y problemas del cotidiano organizacional vienen exigiendo prácticas metodológicas avanzadas originarias y construidas en el interior de la sociología. Este artículo discute y demuestra la utilización, de forma integrada, de prácticas metodológicas originarias de la Tradición Española de Investigación Social Cualitativa y, que, en los Estudios Organizacionales brasileños, ya tiene su espacio desde mediados del año 2000 específicamente el Análisis Sociológico del Discurso (ASD) y, su principal técnica de recolecta - el Grupo de Discusión (GD). Tales metodologías ya son bastante teorizadas e incluso practicadas en nuestro campo, pero todavía no habían sido aplicadas de forma asociada en los EORs brasileños. Para contribuir a la posibilidad de ampliación de la utilización de las metodologías y auxiliar la práctica de los investigadores interesados, este artículo tiene como objetivo principal presentar los principales procedimientos - abstraídos del interior de un "caso ejemplar" -, es decir, revelar la forma como se manifestó la aplicación de las metodologías de Grupo de Discurso, cuyo "discurso grupal" fue analizado por los procedimientos y módulos del Análisis Sociológico del Discurso. El delineamiento, los participantes, la teorización del estudio en sí se detallan brevemente en el capítulo introductorio sólo a modo de contextualización. El objetivo, por lo tanto, de este trabajo metodológico redactado bajo la forma de "caso ejemplar" reside en contribuir principalmente

REAd | Porto Alegre - Vol. 24 - No 1 - Janeiro / Abril 2018 - p. 30-60 
a la visualización gráfica de los procedimientos en un estudio empírico que utilice tales metodologías de forma integrada. Los dos primeros capítulos introducen al lector en el universo de las metodologías de GD y ASD, su historicidad, influencias epistémicas, conceptos, el papel del investigador, entre otros elementos. Al final, emerge el ejemplo - bajo el mando de un cuadro-síntesis orientador de la construcción e interpretación de Representaciones Gráficas (topográfica) acerca de cada procedimiento modular.

Palabras-clave: Análisis Sociológico del Discurso. Grupo de Discusión. Análisis Cualitativo. Consumo de Belleza.

\section{INTRODUÇÃO}

É sabido que as abordagens de Análise do Discurso mais conhecidas e praticadas por pesquisadores de ciências humanas, sociais, bem como das sociologias aplicadas, são as perspectivas francesa e a anglo-saxã. Gordo (2008) indica, entretanto, uma prevalência um pouco distinta da classificação tradicional de abordagens discursivas. O autor propõe três aproximações em Análise do Discurso, a saber: (a) Escola Francesa de Análise do Discurso (análise internalista ao texto); (b) Escola Crítica do Discurso (análise externalista ao texto); (c) Escola Qualitativista Crítica de Madrid, no interior da qual emergiu a Análise Sociológica do Discurso (ASD) - objeto principal deste artigo -, ainda praticamente inexistente na maioria dos manuais e coletâneas sobre Análise do Discurso, porém já em certa medida conhecida no Brasil. Diferente das perspectivas "informacional-quantitativa", "estrutural-textual", representadas, respectivamente, pela Análise Clássica do Conteúdo e pela Escola Francesa de Análise do Discurso, a ASD surge distanciando-se da própria Análise Crítica do Discurso Anglo-Saxã (ACD) (ALONSO, 1998; RUIZ RUIZ, 2009; GODOI, 2010).

Emergindo da tradição espanhola de pesquisa social qualitativa, a ASD consiste em uma síntese particular e específica das anteriores (GORDO, 2008), no sentido que inclui tanto a necessidade de análise internalista (debruçar-se sobre o texto materializado) quanto externalista (com ênfase no sujeito social, e consideração da linguagem como espaço de disputa de poder, conflito e ideologia entre os sujeitos). Faz-se importante ressaltar que a análise internalista relaciona-se à dimensão cognitiva e conceitual, e preocupa-se com o modo como é construído no interior do texto, enquanto a análise externalista leva em consideração as influências de fatores sociopolíticos, econômicos e culturais do sujeito social. 
A Análise Sociológica do Discurso, conhecida em todo mundo hispano-ibérico, França e até EUA, segue bastante desconhecida no Brasil em todos os campos do conhecimento, partindo daí uma das relevâncias deste caso metodológico exemplificador, uma vez que os EORs vêm saindo nos últimos dez anos na frente de muitas áreas no ato de adaptar, sistematizar, criar e conduzir metodologias qualitativas.

Godoi, Coelho e Serrano (2014) historicizam que a Análise Sociológica do Discurso (ASD) emergiu dentro da Escola Qualitativista Crítica de Madri, mais precisamente no início dos anos 1970, e passou a constituir o principal eixo teórico-metodológico de pesquisa qualitativa no país. Paradoxalmente, no centro da falta de liberdade política e de pensamento (PEINADO, 2002), contra o saber oficial, e permeado por práticas de contestação (atreladas à Guerra Civil Espanhola e ao regime de Franco que perdurou 40 anos), surge uma intensa reflexão sobre os problemas sociais, capaz de produzir um redirecionamento da investigação da linguagem, entendida a partir desse momento como discurso social. Essa tradição surge, portanto, como algo inteiramente novo naquele contexto, contrário ao formalismo instrumental da sociologia empírica e como, narra Callejo (2001), foi construído com os materiais críticos do momento: Estruturalismo Francês, Teoria Psicanalítica e Escola Crítica de Frankfurt. Em torno da ASD, portanto, se estabeleceu uma boa parte da fundamentação metodológica dos partidários dos métodos qualitativos na Espanha.

A tradição discursiva sócio-hermenêutica e pragmática da ASD é associada aos trabalhos, principalmente de três gerações: Ibáñez (1979; 2010); Ortí (1986); De Lucas e Ortí (1995), formando a primeira geração desta Escola (pode-se dizer que a primeira geração criou uma forma de pensamento, mas não chegou a constituir uma Escola de AD). A segunda geração da Escola Qualitativista Crítica de Madrid e, consequentemente, da ASD tem como nomes principais: Conde (2008; 2009), Ruiz Ruiz (2009), Alonso (1998; 1999); MartínCriado (1992), para mencionar alguns. O principal papel desempenhado nesta etapa da história da pesquisa qualitativa espanhola - sempre muito atrelada aos fatos políticos, sociais econômicos e ideológicos do país - foi a sistematização de uma forma de pensar, por certo não manualesca e exageradamente formalista.

A Tradição Espanhola de Pesquisa Social Qualitativa, ou a Escola Qualitativista Crítica de Madri - constituem também a origem, da prática de Grupo de Discussão, de origem europeia e dialética (GD) - como prática de coleta - nosso outro objeto neste artigo exemplificador metodológico. A prática de Grupo de Discussão (BRITO, 1999; 2001; CALLEJO, 2001; 2002; GODOI, 2015) é de amplo domínio da maior parte das ciências 
sociais e humanas. Entretanto, no cenário dos Estudos Organizacionais brasileiros permanece desconhecido ou conhecido como praticamente sinônimo de Grupo Focal (episteme positivista mertoniana) - em sua versão anglo-saxã positivista atrelada ao nome de Merton. São inúmeras as distinções - de ordem epistemológica, metodológica e prática entre Grupo Focal (GF) e Grupo de Discussão (GD) - distinções estas que também não se reduzem ao papel mais ou menos diretivo do moderador. As características de utilização e de delineamento homogêneo e simétrico do GD podem ser observadas na discussão deste artigo, bem como visualizadas no caso exemplar, uma vez que o "discurso grupal" foi a técnica embrionário do estudo exemplificador.

A opção pelo uso de práticas metodológicas originárias da Tradição Espanhola de Pesquisa Social Qualitativa (DE LUCAS; ORTÍ, 1995; ALONSO, 1998; CALLEJO, 2001; CONDE, 2009; IBÁÑEZ, 1979; ORTÍ, 1986; 2001; 2010; RUIZ RUIZ, 2009), deu-se por acreditarmos que as temáticas e problemas do cotidiano organizacional emergente vêm exigindo metodologias - tanto de coleta quanto de análise de material empírico - originárias e construídas no interior da sociologia - ou seja, com mais tradição de amplitude multidimensional (sujeito-grupo-organização e sociedade) e também por nos caracterizarmos como Sociologia aplicada, desprovidos quase sempre de criar métodos que ainda não existem nas ciências de origem das quais não podemos nos afastar.

Este artigo pretende discutir e demonstrar a utilização, de forma integrada, das principais práticas metodológicas originárias da Tradição Espanhola de Pesquisa Social Qualitativa e, que nos Estudos Organizacionais brasileiros, já tem seu espaço desde meados do ano 2000 - especificamente a Análise Sociológica do Discurso (ASD) e, sua principal técnica coleta correlata - o Grupo de Discussão (GD). Tais metodologias já são bastante teorizadas e inclusive praticadas em nosso campo, porém ainda não haviam sido aplicadas de forma associada nos EORs brasileiros. Para contribuir para a possibilidade de ampliação da utilização das metodologias e auxiliar a prática dos pesquisadores interessados, este artigo tem como objetivo principal apresentar e permitir a visualização por meio de Representações Gráficas (topográficas) dos principais procedimentos da ASD - abstraídos do interior de um “caso exemplar" -, ou seja, revelar a forma como se manifestou a aplicação das metodologias de Grupo de Discurso, cujo "discurso grupal" foi analisado pelos procedimentos e módulos da Análise Sociológica.

O caso exemplificador escolhido é um "recorte" da aplicação das metodologias em abstraídas de estudo mais amplo acerca do discurso feminino sobre o consumo da beleza desenvolvido com mulheres de duas instituições - professoras e alunas - que formaram seis 
GDs homogêneos também por idade, nível de renda e grau de utilização de produtos cosméticos, inicialmente. O estudo exemplificador teve como objetivo compreender o discurso feminino de duas instituições de ensino no sul do Brasil, no que tange às práticas de consumo de beleza materializadas em produtos estéticos, bem como as origens das crenças incorporadas de padrões culturais de beleza que induzem a estas práticas de consumo. Entender o fenômeno do consumo de beleza através do discurso feminino exigiu, inicialmente, a compreensão do conceito de consumo pós-moderno na sociedade contemporânea (LIPOVETSKY, 1989; BAUDRILARD, 2010).

\section{GRUPO DE DISCUSSÃO COMO PRÁTICA GRUPAL DE COLETA DE DADOS}

A técnica do Grupo de Discussão (GD) - (BRITO, 1999; CALLEJO 2002 LEON, 2007; DOMINGUEZ; DAVILA, 2008; IBÁÑES, 2010; GUTIÉRREZ, 2011; GODOI, 2015) surgiu na Espanha, também no interior da Pesquisa Social Qualitativa Espanhola comandada por Ibáñez (1979) no momento em que se desenvolvia o capitalismo de consumo contrário à exclusividade massiva dos surveys objetivistas no país. O Grupo de Discussão é atrelado, portanto, à história política, social e econômica do país e possui raízes teórico-práticas, diferenças epistemológicas que o posicionam em um lócus bastante contrário à técnica do Grupo Focal (FC). De origem norte-americana, o grupo focal foi desenvolvido a partir das técnicas de entrevistas grupais como instrumentos de análise social e psicoterapêutico, comandado por Merton, Fiske e Kendall nas décadas de 30 e 40.

O Grupo de Discussão consistem em uma prática mais próxima do discurso social, informal espontâneo, no qual tem lugar os conflitos ideológicos sociais. No entender de Ortí (2010), com esta técnica livre ou aberta, aspira-se reproduzir o discurso ideológico cotidiano ou discurso básico sobre a realidade social de uma classe ou estrato homogêneo (referente à amostra) e simétrico (referente ao discurso), representado por uma amostra estrutural de sujeitos sociais. O que se pretende no GD é, principalmente, melhor interpretar em seu contexto os valores motivacionais afetivos, suas crenças e expectativas, assim como, a projeção de seus desejos, resistências e temores, conscientes e inconscientes em torno do problema investigado. Essa situação faz emergir no grupo emoções básicas, conflitos e as normas sociais dominantes vinculadas ao tópico investigado na macrossituação da classe ou estrato social, a qual os membros do grupo pertençam. O GD, postulam Cano e Rubio (2005), propicia a produção livre do discurso através da discussão do tema proposto, reproduzindo em sua composição e dinâmica das situações sociais de referência e 
confrontação ideológica das atitudes e representações sociais a respeito do tema. Em contrapartida, Alonso (1998) mostra que o grupo de discussão visa de "consenso" ao final da sessão, ou seja, busca alcançar acordos sobre os sentidos das representações sociais.

A formação do grupo acontece pelo mediador (pesquisador) ou por contactadores - que convocam os grupos e provocam um tema de discussão sem "fornecer o consenso" que se espera seja construído pelo grupo ao final. O pesquisador determina um espaço para acontecer a reunião e limita o seu tempo, em geral de duas horas - como postulam quase todos os autores do método (BRITO, 1999). A seleção dos participantes articula-se em duas operações: a determinação algébrica das classes dos participantes e o contato concreto mediante redes topográficas com os participantes (IBÁÑEZ, 2010), devendo incluir-se nos grupos os sujeitos que reproduzem mediante seu discurso relações relevantes (IBAÑEZ, 2003).

Convém compreender que a representatividade do grupo de discussão não é estatística - mas estrutural -, pois tem por objetivo tanto captar e representar as posições típicas, quanto a posições extremas que compõem a diversidade do campo social estudado (PEREDA; PRADA; ACTIS; ORTÍ, 2010). O número de participantes de um grupo de discussão está condicionado a cada caso e pode variar entre seis a 12, segundo a maioria dos autores estudados. Já para Ibañez (2010), o número de participantes deve ser entre cinco e dez.

Em relação ainda ao moderador, Ortí (2010) levanta a necessidade deste não poder introduzir juízos de valor sobre o tema, a necessidade de adaptar à linguagem e às características e alerta de que no GD - diferente do grupo focal - o mediador não ocupa posição central na mesa, pois não é líder e espera que os sujeitos dialoguem entre si, não com ele. Além disto, cabe ao moderador intervir o mínimo possível, a não ser que o grupo se cale ou entre em conflito ou derive para outro tema, ou um líder espontâneo monopolize a discussão. Ibáñez (1979) prescreve que no Grupo de Discussão, o discurso é provocado explicitamente pelo moderador e todos os elementos da situação tendem a provocar o discurso do grupo implicitamente. O grupo de discussão é um grupo simulado e manipulável. Simulado porque é um grupo imaginário que tem sua existência, vinculada à produção de um discurso em um determinado tempo e espaço, sendo que este discurso é sua única possibilidade para interromper o silêncio e as descontinuidades. A manipulação acontece porque o mediador tem na mão todos os fios que movem o grupo, tem o poder para assinalar o espaço e controlar o tempo, também tem o poder de determinar quantos são os membros e 
quem vai participar do grupo, e ainda lhe cabe também a decisão de quando este grupo nasce e quando morre.

Trabalhamos neste estudo acerca da compreensão do discurso feminino sobre o consumo da beleza com seis grupos de professoras e alunas (que já atuou como critério de separação da amostra estrutural); em duas universidades. Outros critérios de separação (homogeneização) foi o acesso que tivemos ao nível socioeconômico, homogeneização por faixa etária e - ligado aos objetivos da investigação - grau de utilização de produtos cosméticos (percentual da renda comprometida com estes gastos). Note-se que os critérios de separação no interior dos grupos precisam estar relacionados ao objetivo da pesquisa, por este aplicamos, anteriormente à formação dos grupos - no momento de convidar as pessoas participar -, um breve questionário sócio demográfico e com o principal objetivo de conhecer os sujeitos no critério central: uso de produtos cosméticos específicos para cabelos (delimitamos inicialmente ao extremo a amostra estrutural, uma vez que sabíamos ser o universo do consumo da beleza feminina muito grande). Evidente que apesar de homogêneos, não se consegue nunca, no interior dos grupos, simetria no discurso, que passou a circular por imagináveis elementos artificiais, culturais e já naturais que envolvem a própria mulher como mercadoria rendida às pressões de consumo da beleza. Não utilizamos o que se se chama tradicionalmente de roteiro, mas um plano de reunião como um instrumento que consiste em uma ordenação temática de interesses para os objetivos da investigação e do nosso papel, mas aberto no primeiro horário e, caso necessário, um pouco mais dirigido (BRITO, 2001).

\section{ANÁLISE SOCIOLÓGICA DO DISCURSO COMO NÍVEL DE APROXIMAÇÃO DO DISCURSO}

No contexto deste estudo trabalhamos, portanto, com a Análise Sociológica do Discurso (ASD). Esta tendência está vinculada à Tradição Espanhola de Investigação Social Qualitativa (IBÁÑEZ, 1979; 2010; ALONSO, 1998; ORTÍ, 2001; CONDE, 2008; RUIZ RUIZ, 2009, dentre outros), comandada principalmente pela Escola Qualitativista de Madri, emergiu no início dos anos 70. No entanto, os primeiros passos e usos desta abordagem iniciaram-se ao final da década de 50 e concretamente nos anos de 60, quando foi dado início à investigação de mercados na Espanha, momento a introdução do capital transnacional traz a flexibilização do regime franquista e seu reconhecimento por parte da comunidade internacional. Este é o início de um novo modelo de consumo de massas instaurado naquela época e que implicou na necessidade de investigações centradas nos potenciais consumidores. 
A partir de 1973, ainda durante a ditadura de Franco, nasceu o edifício teórico e metodológico da Análise Sociológica do Discurso, que passaria a se constituir como o núcleo fundamental da pesquisa qualitativa na Espanha (RUIZ RUIZ, 2009; GODOI; COELHO; SERRANO, 2014).

No entender de Conde (2009), a Análise Sociológica do Discurso como um estilo de investigação social, distante de formalismos automáticos de aplicação universal, pretende realizar a investigação com maior rigor possível, tendo um objetivo implícito em cada estudo concreto a fim de melhorar a compreensão dos fenômenos sociais. Os fenômenos com os quais trabalha a ASD residem especialmente na inter-relação do mundo simbólico, do mundo ideológico e os processos de manutenção e mudanças de uma determinada ordem social: a sociedade capitalista e de consumo que domina os países ocidentais. Esse estilo foi configurado a partir dos estudos seminais de Jesus Ibáñez, Alfonso Ortí e Ángel de Lucas primeira geração de estudiosos da ASD -, núcleo de investigadores que está na origem de certa tradição espanhola na investigação social interessados em discursos grupais que possam ser expressos ao longo de uma dinâmica.

A ASD tem-se constituído a partir da adoção e adaptação pelos sociólogos de métodos de análises desenvolvidos por outras ciências sociais, o que produz algumas semelhanças parciais com a análise realizada pela linguística, etnografia, antropologia e psicologia social, para mencionar algumas (ALONSO 1998; 1999; CALLEJO, 1999; RUIZ RUIZ, 2009). Mais do que um método para analisar discursos sociológicos, o que se encontra na literatura é uma série de práticas e procedimentos que os sociólogos têm usado de forma diferente no trabalho profissional. Com a finalidade de explicitar as bases epistemológicas da ASD, discutimos na elaboração deste capítulo principalmente as formulações semelhantes de dois dos principais mentores do método, a saber, Ibáñez (1979; 2010) e Ortí (2010), bem como autores que neles se fundamentaram.

Ibáñez (1979; 2010) considera e analisa três perspectivas epistemológicas na pesquisa social: a distributiva, a estrutural e a dialética. Estas perspectivas pontuam de formas diferentes os três níveis integrados do desenho da investigação social: a perspectiva distributiva (empirista) enfatiza o nível tecnológico da pesquisa (o como se faz); a perspectiva estrutural atribui maior peso ao nível metodológico (o porquê se faz); e a perspectiva dialética, por sua vez, diz respeito, principalmente ao nível epistemológico da pesquisa (para quem se faz). Antes de descrever estas perspectivas, Ibáñez (1979) elabora uma explicação de uma dupla ruptura em ciências sociais: a) a ruptura estatística, que pretendeu fundar uma posição e uma forma de observação neutralizadora da ideologia do observador; e b) a ruptura 
linguística que, pautada na desconstrução e reconstrução do sentido e revelação do sentido latente, originou as perspectivas estrutural e dialética.

Dentro da primeira perspectiva - distributiva, ou disjuntiva, na denominação de Ibáñez (1979) -, locus onde se situam os sociólogos quantitativistas, residem as técnicas de questionário estatístico e coleta de dados secundários de dados. Na crítica de Ibáñez (1979) a esta dimensão, “o sujeito é limpamente evacuado" (2010, p.81) - crítica que diz respeito ao triunfo da objetividade em ciências sociais, na qual "o mesmo sujeito observa o mesmo objeto em diferentes ocasiões" ou "distintos sujeitos observam o mesmo objeto". Trata-se de uma forma "sedentária" de pesquisar - termo utilizado por Ibáñez para explicar o afastamento do campo de pesquisa e a ausência de interação entre sujeitos e objetos (2010, p.81).

A perspectiva estrutural tem como principais práticas de pesquisa a entrevista em profundidade e o grupo de discussão (técnica também desenvolvida na Espanha pelos autores da $\mathrm{ASD}$, que constitui a principal forma de pesquisa qualitativa no país no que tange à coleta de discursos, já aqui teorizada). Ressalva-se que dados secundários também são utilizados no interior desta perspectiva por meio da análise estrutural de textos. Uma das críticas de Ibáñez ao uso exclusivo desta dimensão é de que aqui o sujeito da investigação é integrado, mas apenas "parcial e transitoriamente", ou seja, "taticamente ao nível relacional das comunicações". Trata-se de um tipo de pesquisa que, portanto, não é sedentária como a primeira, e sim "nômade taticamente" (2010, p. 82).

A terceira perspectiva narrada pelo autor - a dialética - tem como modelo prático geral a socioanálise, trabalha "in vivo" e experimenta no campo a expansão e o nomadismo estratégico. Essa perspectiva integra o sujeito da pesquisa de forma completa e definitiva tanto em nível de conteúdo quanto em nível relacional. Desta maneira, pretende-se abolir a separação sujeito (investigador) e objetos (investigados) (IBÁÑEZ, 2010). Ao investigar a ordem social, o pesquisador a transforma e se transforma a si próprio. Neste modelo - no qual o desenho da pesquisa adquire sua mínima expressão -, a análise transforma o que está fechado e coberto em aberto, isto é, coloca em manifesto o latente (IBÁÑEZ, 2010). Nestas formulações do autor percebem-se nitidamente suas influências marxistas e psicanalíticas.

A construção do discurso é referenciada por Conde (2009) não como uma construção procedural, ou como uma espécie de manual com descritivas rotinas, como resposta de análise. Muito pelo contrário, o autor enfatiza que a produção dessa análise é rica em procedimento e tomada como flexível. Enseja, portanto, um dilema metodológico entre as informações empíricas numa relação rica em reflexões sobre a teorização a ser construída. 
Um “processo dialético inacabável” como diria Ibáñez (1979) no qual a construção teórica e a constatação empírica, não se apresentam em uma via de mão única, mas pelo contrário um processo dinâmico, de mão dupla. Como Conde (2009) explica, trata-se de um processo que envolve relações sociais alimentadas pela política, economia e concepções morais, nas quais a aproximação entre a teoria e prática expressão a importância do papel dado à "práxis" como resposta ao caráter pragmático do discurso. Alonso (1998, p. 212) ainda postula a importância da interpretação estar apoiada pelos objetivos de investigação, mas com enfoque à pragmática dos discursos sociais e a pragmática da estratégia de investigação como uma constante articulação.

Sobre este processo de reflexão do ir e vir, entre a prática e a teoria, Ibáñez (2010, p. 322) aponta três problemas definidos por Conde (2009) como níveis de elaboração teórica. O primeiro denominado de nível micro, ou o problema da coleta de dados em sua seleção ou descobrimento -, hipóteses reveladas em resultado à investigação; o segundo denominado de nível médio, o problema de construção, teorias capazes de acolher e dar cobertura aos dados, no qual há certa generalização com base no nível anterior, perfazendo um melhor desenho e maturidade da investigação, e; o último nível ou nível macro, o problema epistémico, envolvendo as hipóteses sociológicas mais gerais, mais amplas, com uma definição de um marco teórico, descrito por Ibáñez (2010) como a "evolução das condições de dupla aplicabilidade dos dados à teoria e da teoria aos dados”. Neste sentido, há um elaborado trabalho de investigação, das práticas de leitura dos textos, que engaja o pesquisador em um processo aberto de hipóteses em aproximação a uma ou outra questão, detalhada por Conde (2009), com uma "segurança progressiva" em que as hipóteses validadas de forma provisória em um determinado texto, passem a ser contrastadas de forma sistemática no conjunto do texto.

O Quadro 1 - mais adiante - é um esboço desse processo flexível, contudo, não circunscrito somente ao GD. Tal linha de pensamento aparentemente procedural tem inspiração no autor Conde (2009) e, de forma nenhuma, o quadro não se fixa somente ao GD, envolvendo um moderador e um grupo com seis ou oito pessoas. Conde (2009) expande sua aplicação a grupos menores com os triangulares, composto por um moderador e três integrantes, à entrevistas individuais, e inclui análise de discursos também sobre textos com origem na impressa.

A princípio, o Quadro 1 possui uma composição didática e distribui-se em quatro Módulos. O primeiro, denominado "Trabalhos práticos iniciais de ASD", estabelece procedimentos logo após o trabalho de campo, como a elaboração de mapas de 
posicionamento com base em aspectos sólidos que descrevem os indivíduos, mas também que levam em consideração, anotações de campo, proporcionadas por intuições, ou sensações captadas ou sensibilizadas pelo pesquisador. Isso se dá também durante o importante momento de transcrição, levando em consideração detalhes pormenorizados das entrevistas revisitadas constantemente, gerando importantes insights. O segundo Módulo é denominado de "Procedimentos de Interpretação em ASD". Conde (2009) escreve que nesta etapa, ocorre a elaboração de Conjecturas Pré-Analíticas, com a elaboração das primeiras hipóteses, constantemente validadas sob o conjunto das entrevistas e seus enunciados ou Estilos Discursivos.

Sobre as demais etapas, pertencentes ao Módulo denominado "Procedimentos de Análise da ASD", Conde (2009) declara a possibilidade de simultaneidade, mesmo que de forma parcial. Envolve características de uma aproximação mediante a sensibilidade do pesquisador, sua experiência de vida, momento em que há uma aglutinação das demais etapas anteriormente apreciadas. Neste aspecto, se toma como ponto de partida, questionamentos envolvendo os Posicionamentos Discursivos - "Quem fala" e "a partir de que posição social se Fala" -, ou seja busca-se identificar posições polarizadas dominantes, uma representação social à generalização do discurso. As Configurações Narrativas, por sua vez, envolvem as questões: De que se fala? Como se organiza a fala?, retratando conflitos e tensões, posições dadas a opiniões divergentes, expressando a mensagem que se manifesta no discurso. A análise dos Espaços Semânticos, por fim, é expressa nos questionamentos: Qual o significado do que se fala? O que está em jogo no que se fala? Qual o significado do que se disse? Tendo por base os objetivos da pesquisa, a análise de distanciamento é caracterizada pela relação dada à análise das Configurações Narrativas e dos Espaços Semânticos. O último Módulo apresenta procedimentos complementares, originários da Teoria Psicanalítica, que auxiliam a elaboração e articulação de um texto escrito capaz em sua narrativa de explicitar a investigação dada ao sistema de discursos.

\section{EXEMPLO DE OPERACIONALIZAÇÃO DOS PRINCIPAIS MÓDULOS E PROCEDIMENTOS NO INTERIOR DO ESTUDO REALIZADO.}

Por certo que os módulos e procedimentos sistematizados por Conde e revisitados pelos autores deste artigo, de forma alguma constituem uma passarela a ser seguida de forma manualesca, didática, sequencial, e cronológica como, por muitas vezes, anseia-se ainda que no interior da pesquisa qualitativa. O que pretendemos aqui sequer é dizer "nós estamos 
praticando assim", mas sim que "esta é uma grande amplitude de formas de praticar ASD". O que significa que, ao conviver pessoalmente com Conde (e com outros autores da ASD que a praticam de forma diferenciada), observamos que sequer ele próprio segue este script, porém segue sim - um percurso que inicia no texto materializado, passa pela construção do contexto e aterrissa na Interpretação Social dos Discursos (ASD).

Podemos dizer que, mesmo em nossa prática, algumas características do Quadro 1 mantêm-se constante: a) os Procedimentos Iniciais servem - e deveriam ser utilizadas até mesmo pelos modelos mais positivistas de análise qualitativa (não existe pesquisador sem caderno de anotações; não existe entrevista sem transcrição literal e por aí segue-se); b) Conde (2009) é incisivo em afirmar que nem a sequência nem a totalidade dos procedimentos precisa ser seguida, porém é também taxativo em diferenciar-se dos modelos neo-positivistas (que iniciam pela análise e culminam com a interpretação), quando prescreve que se deva iniciar pelo módulo interpretativo, uma vez que a interpretação é artesanal, livre arbitrária do pesquisador, quase um chute que se tornará validada ou não a posteriori no transcorrer da tríade dos procedimentos analíticos. No mais, cabe ao pesquisador a arte de interpretar e fazer-se visualizar em cada procedimento por meio das Representações Gráficas criativas.

\section{Quadro 1 - Metodologia de Análise Sociológica do Discurso}

\begin{tabular}{|c|}
\hline MÓDULO - 1. TRABALHOS PRÁTICOS INICIAIS DE ASD. \\
\hline 1 Preparação do Trabalho de Leitura e de Análise dos Textos. \\
\hline 1.1.1. Anotações durante e após o trabalho de campo. \\
\hline $\begin{array}{l}\checkmark \text { Relato das primeiras intuições, sensações, ideias e conclusões das entrevistas realizadas e anotações de } \\
\text { campo. } \\
\checkmark \text { Análise do contexto - fontes discursivas. } \\
\checkmark \text { Identificação de temáticas significativas. } \\
\checkmark \text { Elaboração de mapas de posicionamento e identificação de pontos de conflito. } \\
\checkmark \text { Realizadas desde as primeiras tarefas práticas, em paralelo com a leitura dos textos. } \\
\checkmark \text { Caracterização, classificação e codificação de conteúdos; marcação de expressões, insights, associações, } \\
\text { hipóteses, elementos importantes. }\end{array}$ \\
\hline 1.1.2. Transcrição literal. \\
\hline $\begin{array}{l}\checkmark \text { Tradução das entrevistas. } \\
\checkmark \text { Inclusão de comentários, pausas, saídas, movimentos, intervenientes durante a entrevista. } \\
\checkmark \text { Releitura das transcrições. }\end{array}$ \\
\hline 2 Preparação do Trabalho de Leitura. \\
\hline 1.2.1. Leitura ordenada do corpus do texto. \\
\hline $\begin{array}{l}\checkmark \text { Criação de uma ordem inicial e provisória de leitura (ordem inteligível) das entrevistas, trechos que } \\
\text { compõem o corpus do texto. }\end{array}$ \\
\hline 1.2.2. Leitura literal do texto. \\
\hline $\begin{array}{l}\checkmark \text { Leitura e releitura, atentando para a mudança da forma habitual de leitura. } \\
\checkmark \text { Identificação de peculiaridades geradoras de pistas que conduzem as conjecturas. }\end{array}$ \\
\hline 3 Decomposição e a Abordagem Integral do Texto. \\
\hline
\end{tabular}

REAd | Porto Alegre - Vol. 24 - No 1 - Janeiro / Abril 2018 - p. 30-60 


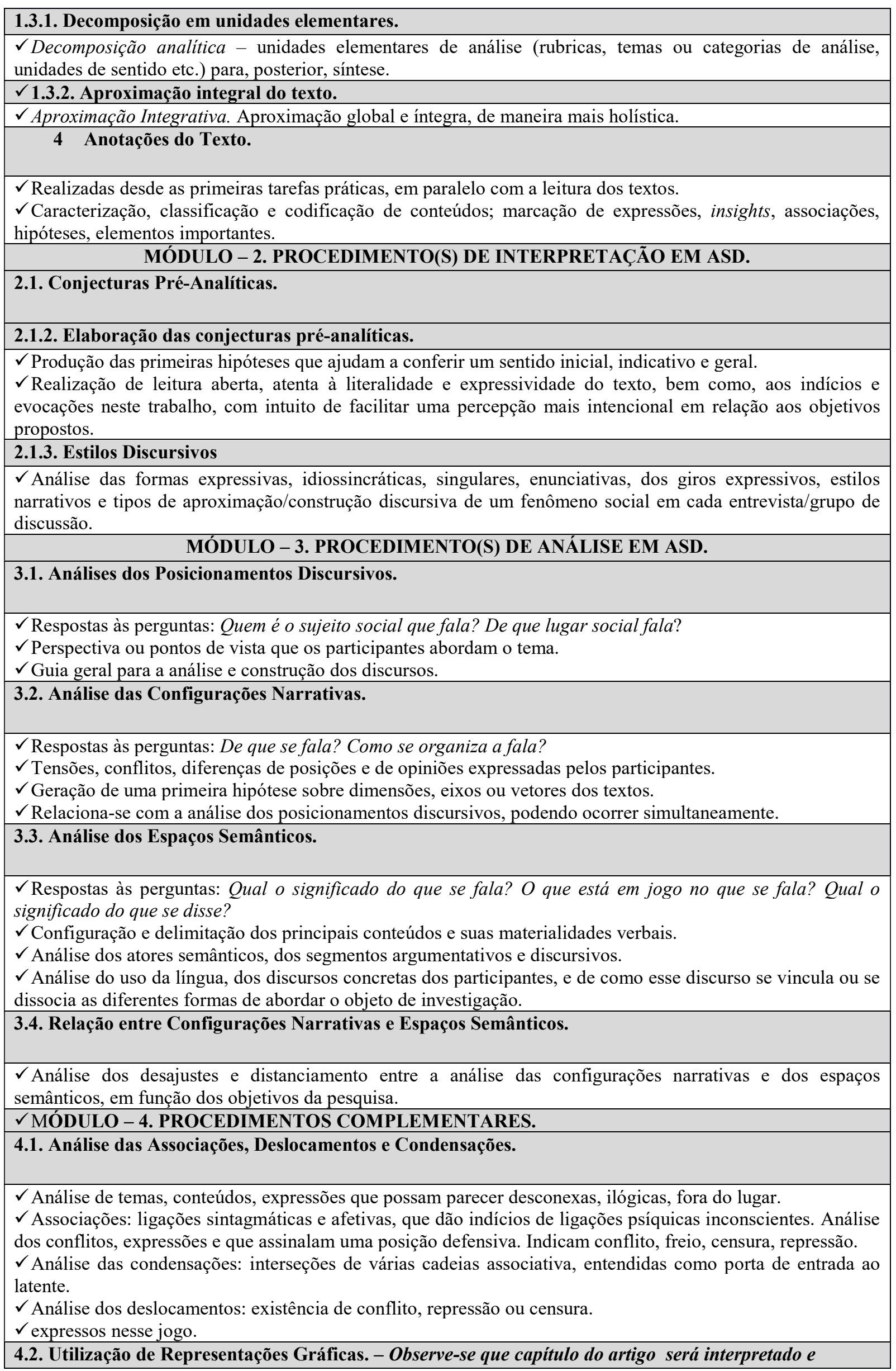


$\checkmark$ Auxiliam na explicitação das conjecturas, isto é, permitem que a intuição (ou conjectura implícita) na gênese do modelo possa formalizar-se e evidenciar-se, distanciando-a desta mera forma de intuição mais inefável.

$\checkmark$ Utilizam-se distintos formatos gráficos: quadros, matrizes, esquemas, figuras que ajudam a visualizar e ordenar os resultados da análise realizada, bem como identificar dimensões mais relevantes das linhas de análise e interpretação.

Fonte: elaborado pelos autores com base em Conde (2009).

A Figura 1 ilustra a sequência não necessariamente cronológica ou didática, proposta por Conde (2009) e por nós interpretada que implica nas seguintes questões: (a) evidente que, como principal representante da segunda geração da Analise Sociológica do Discurso, Conde intencionou propor uma concepção modular de todos os procedimentos que uma prática de ASD pode conter, entretanto, é preciso considerar que muito se preocupa em elucubrar entre o amadorismo e "formalismo", no sentido de que há que traçar um rumo sim aos jovens pesquisadores, porém um caminho em direção à direção criatividade, ao ir e vir entre coleta e análise; entre internalismo e externalismo; (b) a simplicidade da figura implica em que uma das coisas que Conde (2009) propunha - ainda que postulasse não seguíssemos na sequência os procedimentos, residia em não "saltar" módulos, isto é, ao iniciar por procedimentos confirmatórios de análise (confirmatória) - não de interpretação (livre arbitrária do pesquisador) - estaríamos incorrendo em uma inversão em termos de dificuldade, ao final da pesquisa, de qualidade (validade e confiabilidade) da pesquisa qualitativa). Os procedimentos complementares revelaram a forte influência da Teoria Psicanalítica sobre a ASD - juntamente com Marxismo e Estruturalismo Francês. Antigamente, apenas a título de informação que conduzia os Grupos de Discussão e realizava a micro interpretação social dos discursos eram psicanalistas; enquanto sociólogos posicionavam-se por trás do mirror room realizando a macro interpretação social dos discursos.

Após a Figura 1, prosseguimos com breve demonstração da forma como ao menos um procedimento da ASD foi aplicado no estudo com seis Grupos de Discussão cujo discurso grupal consistia no discurso feminino sobre o consumo da beleza. Por exemplo, no trabalho mais amplo constam oito Conjecturas Pré-Analíticas que prosseguiram sendo validadas ou não no transcorrer do trabalho. Por questões de espaço e finalidade demonstrativa, aqui trabalhamos com os Procedimentos Interpretativos; Analíticos; e Complementares, entretanto, com apenas um procedimento de cada tipologia. 


\section{Figura 1 - Síntese dos procedimentos de ASD}

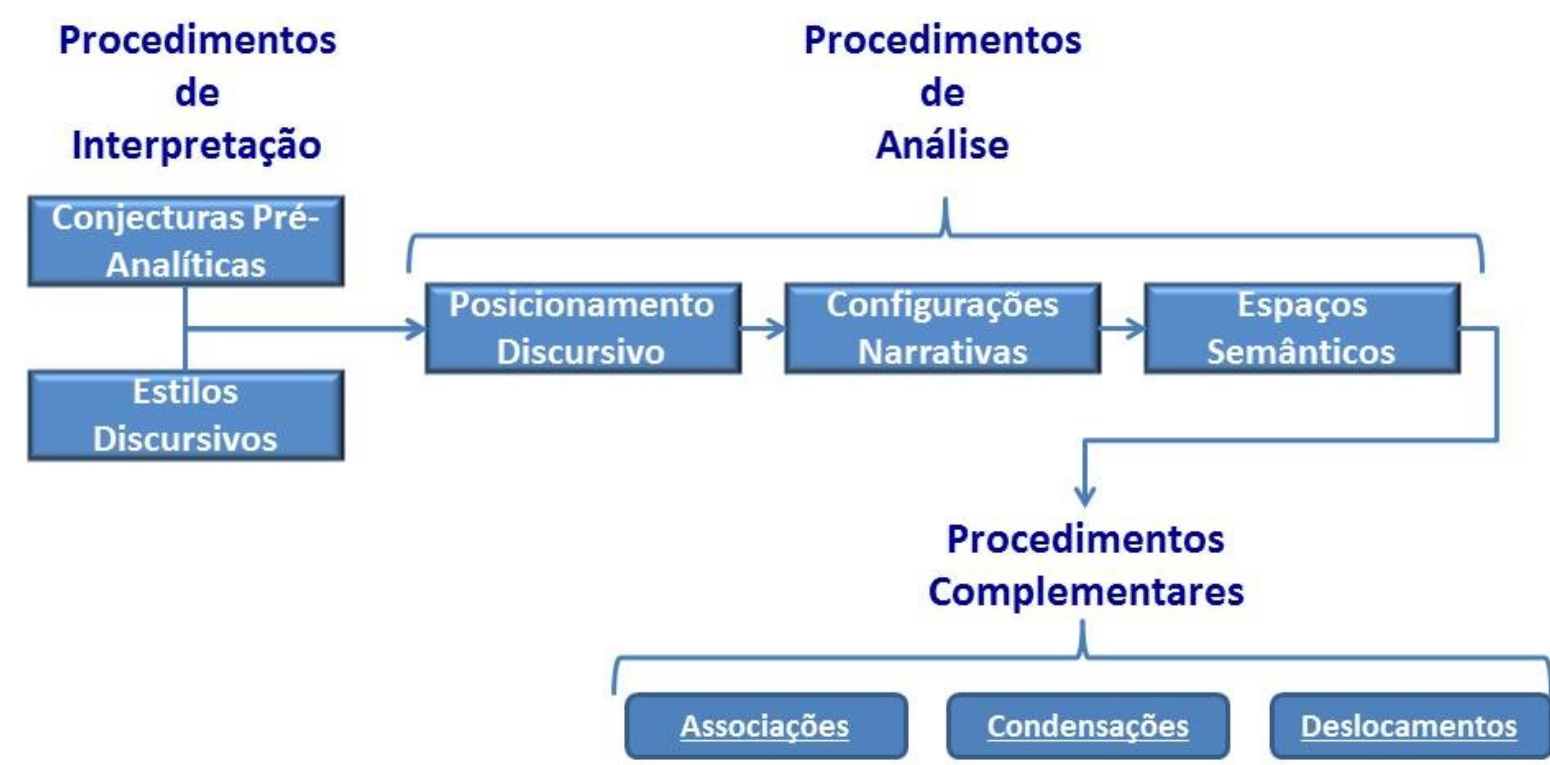

Fonte: elaborado pelos autores.

Como se sabe, as Conjecturas Pré-analíticas são uma produção das primeiras hipóteses que ajudam a conferir um sentido inicial, indicativo e geral. Emergem dos insights das anotações de campo associados aos objetivos de campo. Neste estudo, o cuidado com o cabelo é compreendido como um dos rituais mais importantes, caros, complexos e muitas vezes extensos e cansativos do universo de beleza feminino. Envolve atividades, tais como: lavagem, secagem, alisamento, cacheamento, hidratação, escovação, tintura, dentre outras. Esse tipo de cuidado acaba sendo o principal gasto para as mulheres. A Figura 1 permite iniciar um esboço de Pré-Conjectura Analítica - baseadas em rituais e padrões, porém ainda provisórias e fragmentada. Os quadrantes retangulares representam os Estilos Analíticos originários dos condicionamentos das mulheres participantes do GD na sociedade condicionamentos políticos, ideológicos, culturais, etc. - que determinam idiossincrasias e singularidades na fala. Estão aqui sintetizados por questões de espaço, porém são originários do discurso direto dos GDs. 


\section{Figura 2 - Conjecturas pré-analíticas provisórias e estilos discursivos}

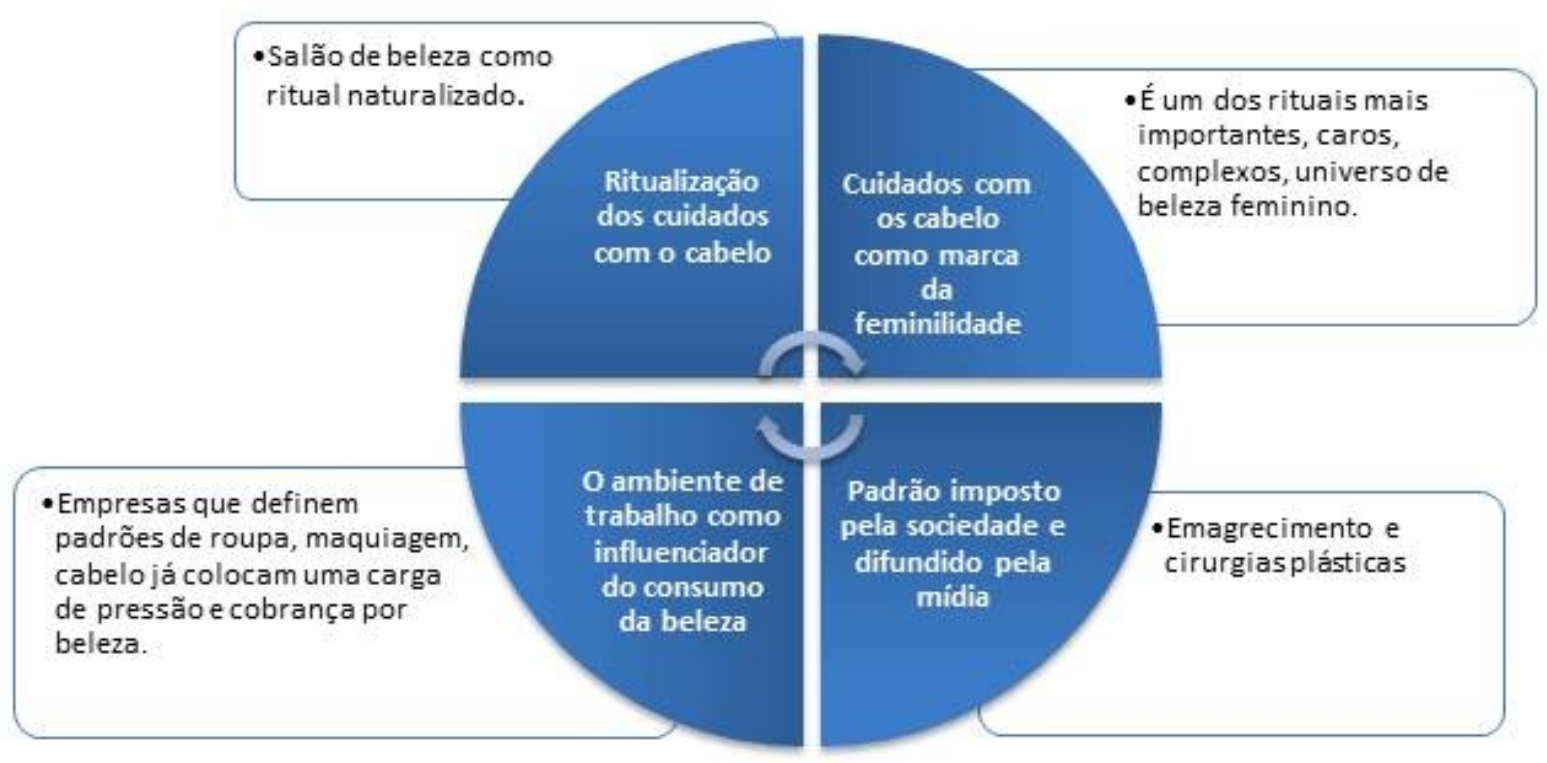

Fonte: elaborado pelos autores.

Na Figura 2 se pode perceber quatro fragmentos de Conjecturas Pré-Analíticas complementares e ainda provisórias. Nos retângulos externos residem estilos discursivos advindos de condicionantes da forma como as mulheres pesquisadas inscrevem-se na sociedade, ou seja, a forma como são manipuladas pela mídia, pelas colegas de trabalho e “escravizadas pelo padrão imposto pelas próprias empresas”. Dois aspectos são importantes serem apontados ao tratar de condicionantes dos estilos discursivos - sua literalidade; e seus aspectos ideológicos, políticos, socioeconômico, de gênero, dentre outros que determinam a inscrição destas mulheres na sociedade do consumismo. Os Estilos Discursivos foram abstraídos de conjunto de discursos diretos.

As setas circulares internas culminam no fenômeno da ritualização principal que emerge no discurso feminino e que aqui está por se configurar - os cuidados associados ao consumo da beleza marcado aparentemente pelos cuidados "superficiais" com os cuidados com o cabelo. Antes de configurar a Conjectura definitiva - hipótese explicativa deste momento discursivo, faz-se necessário compreender por meio da Figura 3 a existência não só de uma circularidade discursiva, mas de uma direcionalidade - determinação.

A Figura 3 indica o fato de as ritualizações dos cuidados e do consumo ligado à beleza dos cabelos apareceram nas narrativas de todos dos Grupos de Discussão. Identificamos que estes processos são importantes para tais mulheres consolidarem sua identidade feminina e sentirem-se pertencentes aos seus grupos sociais e de gênero. Da 
mesma forma, a questão do "padrão" - mais à frente melhor trabalhado, porque possui diferentes origens, tange aqui à imposição da empresa e das colegas de trabalho - ou seja, aparece de forma incisiva em praticamente todos os GDs. Interpretamos que a necessidade de arrumar-se (unhas, cabelos, maquiagem e salto-alto) cria uma espécie de "pseudopadrão informal" entre as mulheres no ambiente de trabalho com a finalidade de reduzir o grau de competição evidentemente existente em torno da beleza nas organizações. Esta figura que nos conduz a "hipótese" - Conjectura explicativa, por certo já não é internalista do texto e sim contextual, externalista, passando pela nossa interpretação dos sistemas de discursos.

\section{Figura 3 - Conjectura pré-analítica e estilos discursivos - salão de beleza como ritual naturalizado}

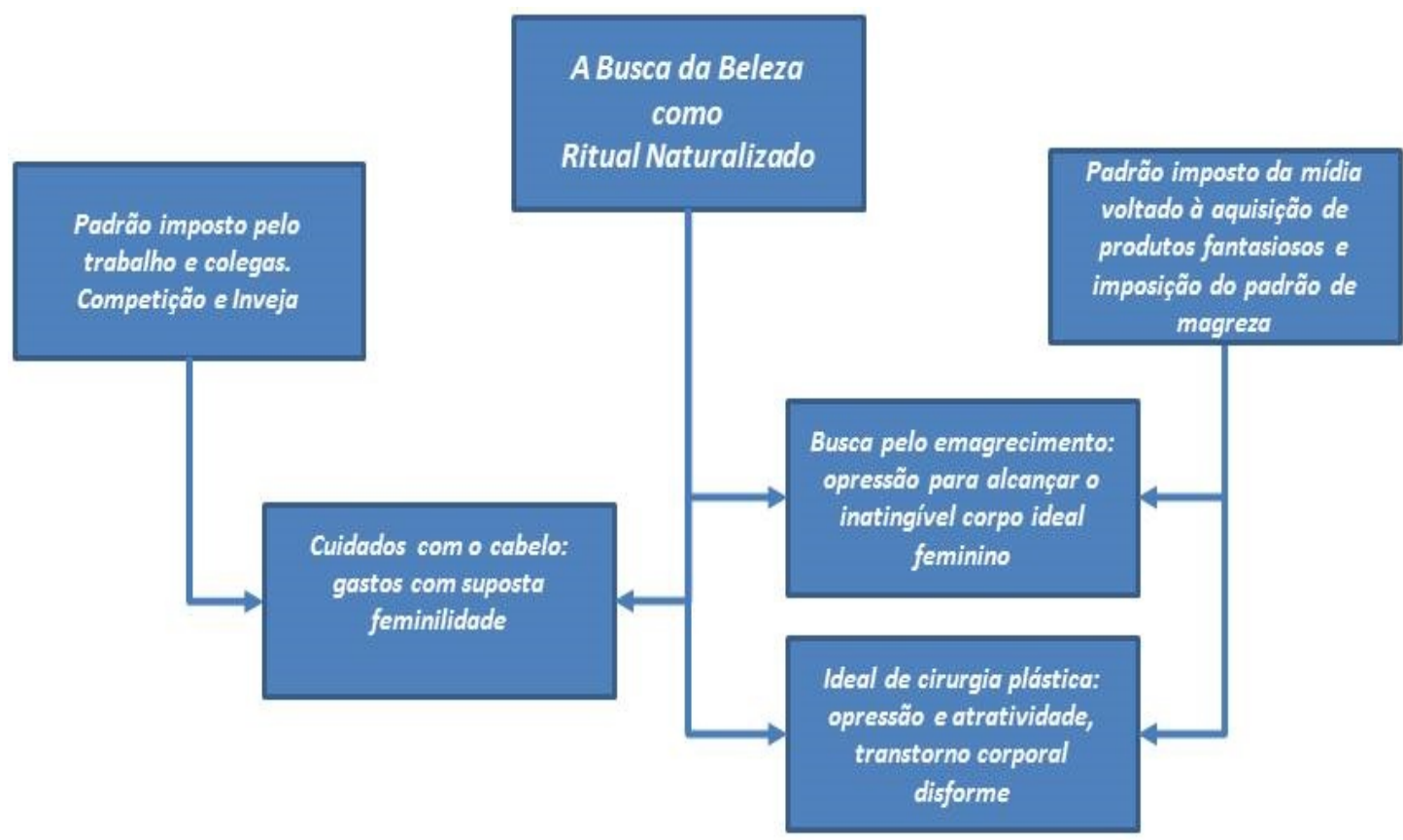

Fonte: elaborado pelos autores.

Sentimo-nos, então, aptos à formulação da "hipótese explicativa" - Procedimento Interpretativo central da ASD - Conjetura Pré-Analítica explicativa deste módulo do recorte de um estudo mais amplo. A Conjectura Pré-Analítica principal que explica o fenômeno da compreensão buscada pelos diversos tipos de padrão imposto à mulher pela sociedade - no discurso dela própria - reside, até o momento, na passagem do conceito de Salão de Beleza (aqui como um dos representantes dentre tantos) do artificial (outrora utilizado somente em grandes comemorações) para o cultural disseminado nas práticas do cotidiano sem 
questionamento, para, posteriormente, ao natural (entendido como pressuposto básico, como se sempre tivesse sido desta forma) - ou seja - quase um condicionamento necessário para a sobrevivência no mercado de trabalho. O outro lado da Figura 3 - tipos de padrão impostos à mulher que, juntamente com o trabalho, a deixam praticamente sem opção de ser livre - será trabalhado mais adiante nos demais Procedimentos Analíticos.

E aqui é de gênero, de imposição de gênero que estamos falando. Durante as sessões de práticas fashion de embelezamento que, por vezes, extremamente tecnológicas, são naturalizadas no discurso, os longos rituais, ritos e cerimônias realizada no interior deste não lugar tem como objetivo central, provavelmente, não uma manicure que pode durar "uma semana"; uma "escova" que no dia seguinte já não está, mas aspectos de sociologização permitido somente às mulheres: "fofocas sobre celebridades"; uma relação de "intimidade" com seus profissionais preferidos que supostamente às "compreendem melhor" e "sabem o que elas querem" - fenômeno puramente imaginário. O que queremos dizer que tal processo de interpretação social nos conduz - a partir da Conjectura elaborada a afirmar ser o Salão um lócus que funciona tal como um consultório psicológico capaz de, pela via do suporte psicológico e relacional e dos elogios, elevar a aceitação da mulher no local de trabalho, causar "inveja às amigas" e - por estes motivos - vale à pena investir na fonte de beleza feminina que exige maior dispêndio financeiro mensal.

Passamos agora ao Módulo Analítico da ASD trabalhando com os Procedimentos de Posicionamento Discursivo (Quem é o sujeito social que fala? De que lugar social fala?); Configurações Narrativas (De que se fala? Como se organiza a fala?) e Espaços Semânticos (Qual o significado do que se fala? O que está em jogo no que se fala? Qual o significado do que se disse?).

No intuito de reunirmos as semelhanças e distinções encontradas no discurso dos grupos a respeito do entendimento de padrão de beleza, construímos a Representação Gráfica (Figura 4) que expressa diversas relações em seus eixos, configurando no seu interior por nós denominada "tríade analítica", pois como o leitor poderá verificar, os Procedimentos Analíticos precisam ser tecidos antes. 
Figura 4 - Posicionamentos discursivos, configurações narrativas e espaços semânticos: padrão de beleza na pós-modernidade

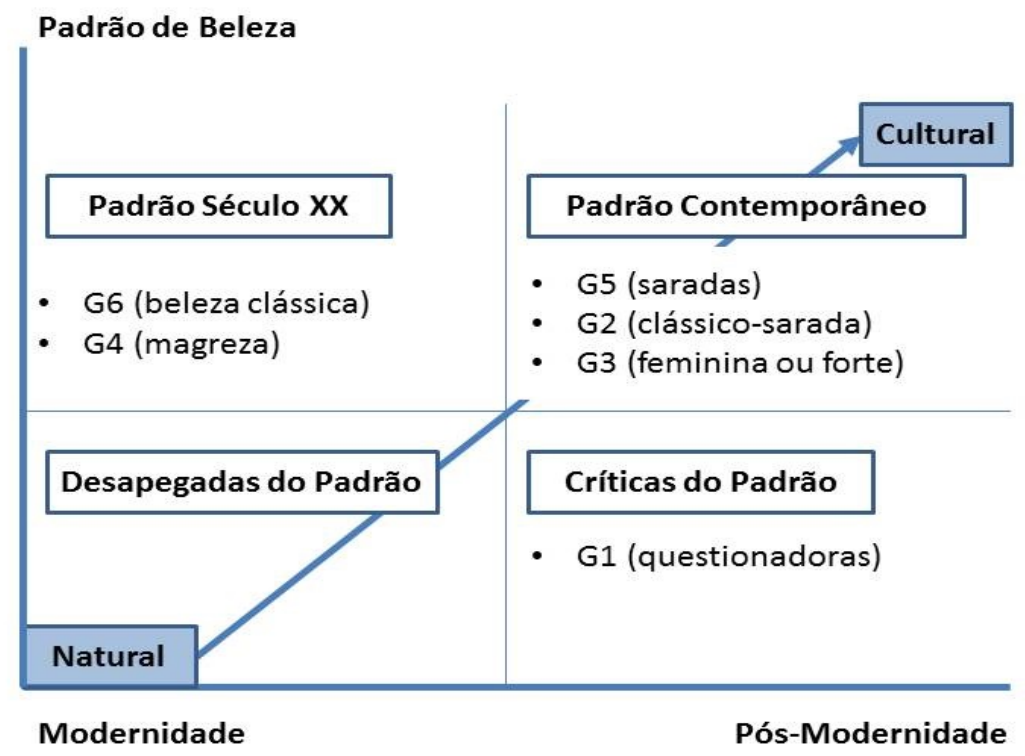

Fonte: elaborado pelos autores.

Com relação aos dois eixos principais, o horizontal identifica a importância e o apego do discurso grupal feminino do padrão de beleza (midiático; do trabalho, etc.), e o vertical à proximidade dos GDs da noção de pós-modernidade (aqui apenas referente ao descentramento de noção real e epistemológica de sujeito auto-referencial e tribal presente em alguns grupos).

Do cruzamento dos dois eixos, formaram-se quatro quadrantes opositivos e diferenciados, portanto quatro Posicionamentos Discursivos predominantes no interior dos Grupos (usamos a simbologia G1, G2, etc. para identificar os seis Grupos de Discussão estudados). Os Posicionamentos Discursivos diferenciados e conflitantes entre os GDs são: Desapegadas ao Padrão; Críticas ao Padrão; Padrão Contemporâneo e Padrão Século XX. As nomenclaturas internas aos quadrantes constituem os agrupamentos, arranjos discursivos aos quais, após a análise conjunta do discurso grupal, atribuímos nomes reforçadores dos Posicionamentos. Trata-se, portanto, das Configurações Narrativas (obtidas da análise do discurso grupal direto) - meio através do qual sabemos que os GDs se diferenciam. Ao passarmos agora para uma explanação mais ampla da Representação Gráfica, implica em que estamos no interior do Espaço Semântico - explanando, que significados estão em jogo nestas narrativas opositivas. 
Explicando, no sentido anti-horário a formação dos quadrantes e tipologias (nomenclaturas utilizadas para representar o discurso feminino no interior de cada grupo): a) baixa atribuição de importância a qualquer padrão e também distância das características da noção de sujeito pós-moderno (MASTELLA; GODOI; 2016) - ocorre que nenhum grupo obteve narrativas tão desapegadas para estar situado neste quadrante absolutamente naturalístico denominado por nós de Desapegadas do Padrão; b) baixo apego a qualquer tipo de padrão, inclusive críticas ao padrão, porém extremamente centradas na noção de sujeito do consumo da pós-modernidade - os grupos aqui situados foram chamados de Críticas do Padrão - apenas um grupo foi aqui situado apenas um GD obteve Configurações Narrativas suficientes para estar neste quadrante e recebeu a denominação nas Configurações Narrativas de Questionadoras; c) elevada importância nos dois eixos, ou seja, discurso associado à noção de sujeito pós-moderno e elevada atribuição de importância ao padrão de beleza - os GDs inseridos neste quadrante receberam a denominação de Padrão Contemporâneo (atual, porém não pós-moderno) em termos de Posicionamento Discursivo e as Configurações Narrativas, que envolveram três tipologias de grupos narrativos, foram chamados de Saradas; Clássico-Saradas; Magras e Fortes; e, por fim, d) o último quadrante com dois grupos Posicionados Discursivamente como Padrão Século XX tais representam baixo posicionamento, na época, em relação à importância hoje atribuída ao padrão - suas Configurações Narrativas foram representadas pelos primórdios da Magreza e da Beleza Clássica.

Além disto, existe um eixo central que traspassa os quatro quadrantes que tem como intenção mostrar que os posicionamentos antigos - como o Desapego do Padrão estão naturalizados, disseminados e não causam estranheza estando inclusive, de certa forma "ultrapassados", enquanto posicionamentos contemporâneos e pós-modernos encontram-se ainda em processo de aculturação e causam ainda alguma estranheza para alguns dos grupos sociais.

Para concluir a compreensão da tríade analítica dos procedimentos que compõem o módulo analítico da ASD passamos agora a recorrer à utilização do "triângulo sêmico" de Lévi-Strauss, que trata de dar conta das possíveis estruturas culturais existentes e latentes de uma determinada sociedade ou grupo social. 


\section{Figura 5 - Posicionamentos discursivos, configurações narrativas e espaços semânticos}

- o conflito cultural na díade artificial versus natural

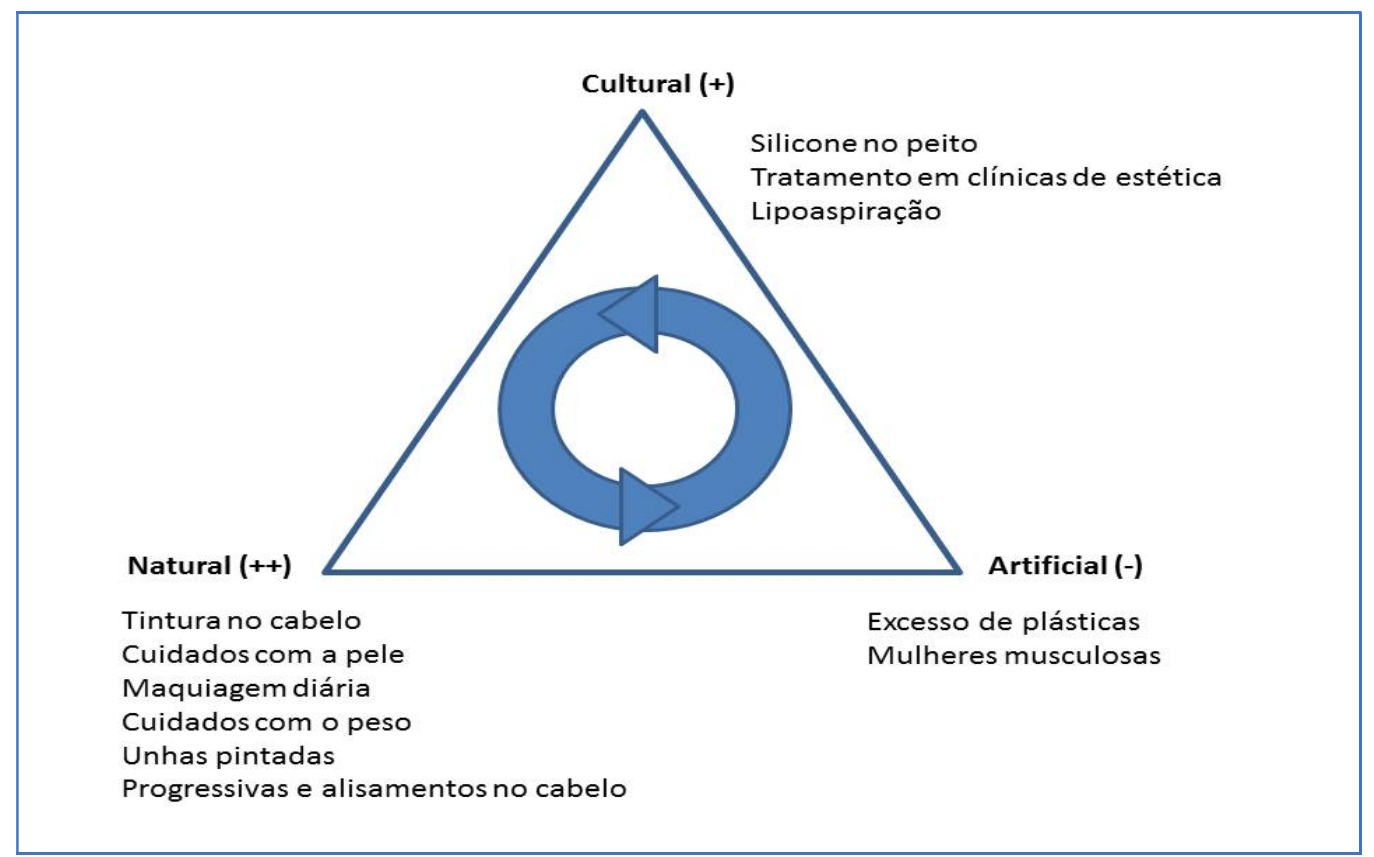

Fonte: elaborado pelos autores.

Esta Representação Gráfica, idealizada por Lévi-Strauss, traz três Posicionamentos Discursivos bastantes diferenciados e visualizados nos vértices (Figura 5) e consiste em é um triângulo em que se localiza em um dos vértices a cristalização de um determinado momento histórico da cultura de um grupo social. O vértice que traz a noção de natural implica em que determinado objeto ou fenômeno já fosse um pressuposto ou algo dado como natural e integrado ao cotidiano e à cultura deste determinado grupo em sua totalidade; b) o vértice que contém a noção de artificial implica na percepção de determinado objeto ou fenômeno como estranho ou anômalo para a cultura de determinado grupo social; e por fim, o terceiro vértice, - a concepção de cultura- como o "meio do caminho" - a passagem necessária - entre natural e o artificial. O campo do vértice cultural implica em objetos ou fenômenos que ainda não são naturais, mas também não causam mais tanta estranheza ao grupo social, tal como explicita Conde (2009). A circularidade no interior da figura significa - no campo do estudo do consumo da beleza e sua infinidade - que tudo aquilo que está exemplificado no interior da Figura 5 que um dia foi totalmente estranho e artificial. Os elementos artificiais deste estudo passaram rapidamente pela intermediação da dissolução na cultura (vértice cultural) e vieram a tornar-se cada vez mais naturais de forma muita rápida no interior das gerações estudadas. Como os diferentes exemplos de 
Configurações Narrativas (obtidas na síntese das ênfase constante nos Discursos Grupais) foram inseridos na Representação Gráfica os principais elementos que atravessam os discursos. Consideramos para efeitos de configurar a tríade analítica dos Procedimentos da ASD, os vértices como Posicionamentos Discursivos opostos e diferenciados e os exemplos inseridos com abstrações do discurso dos GDs agrupadas em Configurações Narrativas centrais, a breve explanação do reconhecido Triângulo do antropólogo Claude Lévi-Strauss (1970) como Espaço Semântico que obtivemos para aprofundar um pouco mais o dito.

Por fim, passamos ao módulo dos Procedimentos Complementares da ASD originários da Teoria Psicanalítica Freudiana - uma das principais influências epistemológicas da ASD, juntamente como o estruturalismo francês e o Marxismo (conforme fora discutido nos primeiros capítulos). Passamos agora a falar, tanto na voz de Freud (Obras Completas), Laplanche e Pontalis (Vocabulário de Psicanálise francês muito reconhecido) e do próprio uso que Conde faz destes conceitos transformando-os em procedimentos Complementares da ASD: Associação; Condensação e Deslocamento.

Figura 6 - Procedimentos complementares da ASD - da associação livre à censura estrutural

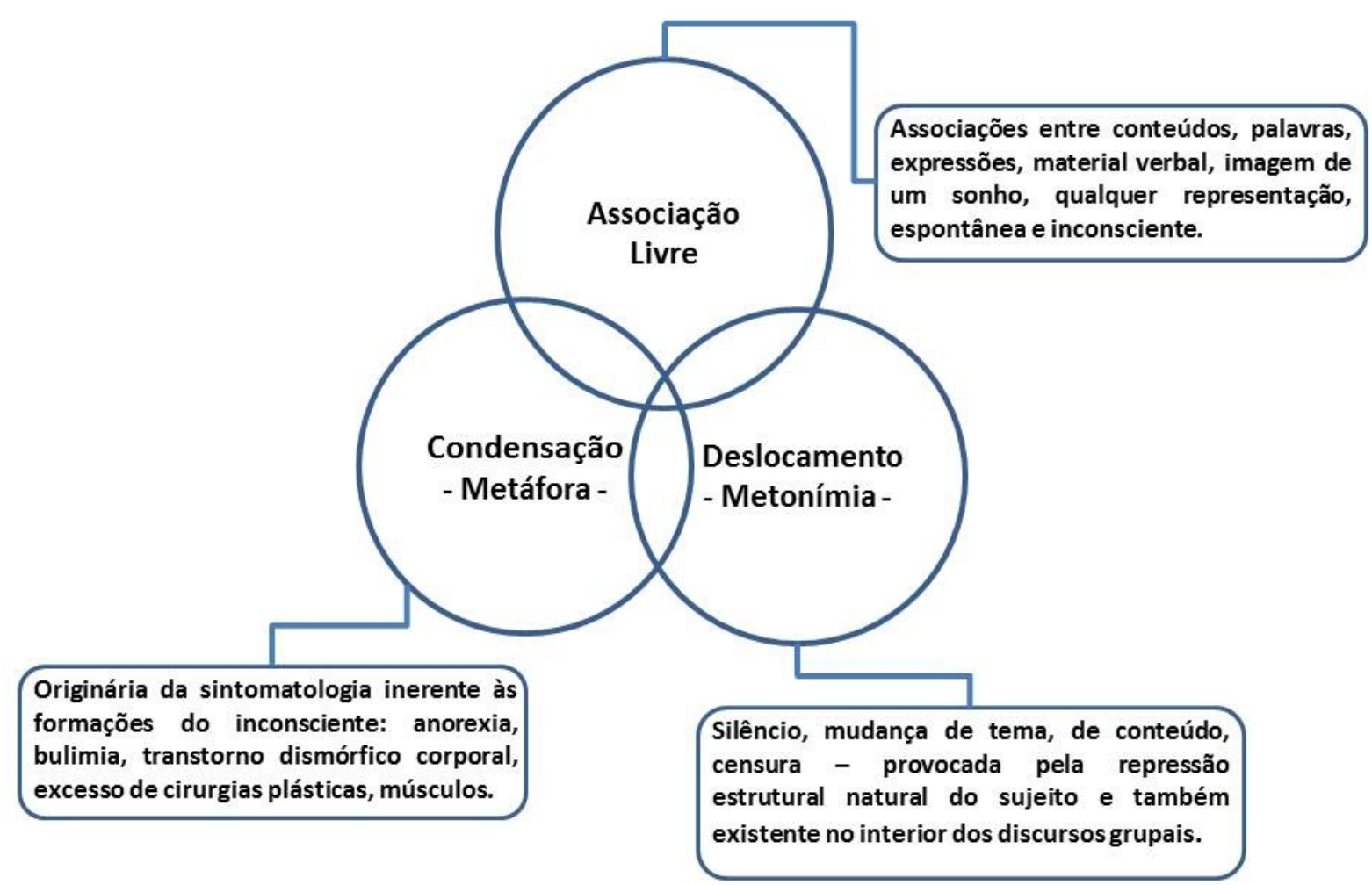

Fonte: elaborado pelos autores.

REAd | Porto Alegre - Vol. 24 - No 1 - Janeiro / Abril 2018 - p. 30-60 
A Associação Livre consiste no próprio método da psicanálise que reside em exprimir indiscriminadamente todos os pensamentos que ocorrem ao "espírito" do sujeito, quer a partir de um elemento dado (palavra, número, imagem de um sonho, qualquer representação), e de forma espontânea (LAPLANCHE; PONTALIS, 2001). A partir de Conde (2009), as associações entre uns e outros conteúdos, umas e outras expressões, entre um e outro tipo de material verbal do grupo, por mais que sejam ditas, não são plenamente conscientes de si mesmas. Essas associações seriam constituídas a partir de um espaço comum provocado por campos de forças sociais, simbólicas e energéticas (investimento de energia libidinal em determinado objeto). Trata-se de fios discursivos como associação entre cadeia de marcas de produtos cosméticos, por exemplo. O discurso grupal no interior dos GDs apresentou-se permeado de cadeias associativas com deslizamentos de significantes constantes entre as questões principais aqui trabalhadas relativas à estética e ao consumo da beleza e à ritualização da beleza (Figura 3): o deslizamento de idas e vindas mais frequentes, de uma forma sequencial: rituais no salão de beleza - preocupação com o cabelo - padrão da magreza - imposições imaginárias do ambiente de trabalho - competição entre as mulheres -magreza - padrão da mídia.

A Condensação consiste em um dos modos essenciais do funcionamento dos processos inconsciente, que vemos operar no "sintoma" (anorexia, bulimia) e, de um modo geral, nas diversas formações do inconsciente. Foi nos trabalhos freudianos acerca da interpretação do sonho que este conceito melhor se evidenciou (LAPLANCHE; PONTALIS, 2001). A partir deste momento falaremos sobre esta operação encontrada no discurso dos GDs tal como é compreendida por Conde (2009), como uma figura de linguagem - metáfora - que vem a ser uma espécie de contração, o relato, por exemplo - lócus onde Freud desenvolveu o conceito - do sonho "sonhado" que resulta lacônico extremamente resumido em relação ao sonho "manifesto". Este fenômeno relaciona os conteúdos latentes e articula vários diferentes planos de significações funcionando como a interseção como porta de entrada ao latente. Diversas condensações foram encontradas sistematicamente no discurso dos GDs - formações do inconsciente - (chistes, atos falhos, sonhos, mas o que aqui nos interessa tratar é da metáfora sintomática emergente do discurso das mulheres no interior dos GDs: não apenas as patologias como anorexia, bulimia, transtorno dismórfico corporal traspassaram sistematicamente as sessões. Podemos entender que - aquilo por nós trabalhado na Figura 5 - Representação Gráfica sobre o dilema entre o artificial e o natural na cultura (que atravessou os discursos grupais de forma permanente) inclui também diversas 
condensações inconscientes e metafórica (uma coisa simbolizando outra - outro desejo, tal como excesso de cirurgias plásticas, lipoaspiração, músculos, etc.

Por fim, o último procedimento freudiano utilizado por Conde (2009) como procedimento complementar à ASD denomina-se Deslocamento e é da ordem da figura de linguagem "metonímia” (transmutação - silêncio, mudança de tema, de conteúdo, censura provocada pela repressão estrutural natural do sujeito e também existente no interior de sessões grupais. Na concepção de Conde (2009), o deslocamento ocorre quando durante uma sessão de GD se passa de um tema para outro, ou se muda de conteúdo, ou de expressões significantes ou significados, em virtude de uma parte do grupo desejar mudar de assunto da discussão uma razão aparentemente qualquer. Podemos explicitar um deslocamento estrutural acorrido quando se discutia a respeito da realização de cirurgias plásticas com finalidade estética. Uma das participantes disse da sua vontade de colocar próteses de silicone no peito, e de já procurar mais informações e especialistas para consultar e fazer tal cirurgia. Neste momento outra participante passou a relatar vários casos de amigas suas que, coincidentemente, após terem colocado próteses de silicone no peito, acabaram tendo câncer de mama e vindo a falecer por tal enfermidade. Evidente que tal censura estrutural provocada pela forma de expressão negativa provocou um giro no discurso grupal: o deslocamento incitou tanto o silêncio por parte da maioria quanto também gerou posturas contrárias a tais cirurgias pelos riscos de tais intervenções, enfim a quebra na sequência natural do discurso. As manifestações do inconsciente são, como sabemos, em geral entendidas por não analistas do discurso e pesquisadores principiantes como, "morreu o assunto", "problema do roteiro", "socialmente aceitas como naturais" - enfim, escutadas no sentido lacaniano somente com a "ouvido atento" às mazelas do cotidiano grupal; enquanto o "ouvido que deveria estar “atento" às associações, condensações e deslocamento - parece hoje cada vez mais confiar no gravador.

\section{CONSIDERAÇÕES FINAIS}

No que tange ao objetivo do centro temático do artigo - cabe apenas mencionar que a visão de sociedade pós-moderna e a compreensão do indivíduo que nela habita, tornaram-se fundamentais para o entendimento do consumo e dos cuidados com a beleza feminina. Estes elementos nos proporcionaram, durante a pesquisa prática, a possibilidade de construir uma série de conjecturas principais que emergiram ao longo do processo de análise dos discursos pesquisados: a influência do ambiente de trabalho na motivação aos cuidados 
de beleza das mulheres investigadas; o papel das mídias como influenciadores do padrão e do consumo de beleza; busca pela magreza e cuidados com o cabelo como principais preocupações com a beleza; cobrança social por beleza por parte dos parceiros, amigas e familiares; e a importância da compreensão da beleza como ritualizada. Como sugestões temáticas de pesquisas futuras relativas ao estudo prático aqui relatado, de forma subjacente, acreditamos que possam emergir temas relacionados a distorções ligadas à área de beleza, como de mulheres viciadas em academias, mulheres com tendências anoréxicas ou bulímicas, mulheres que buscam todos os tipos de tecnologias e invasivas ou não invasivas, pois este tema apresenta relevância social e é direta ou indiretamente causado por toda uma indústria que promove e impõe a beleza como algo fundamental e imprescindível para vida das pessoas.

Passando ao enfoque principal e objetivo deste artigo - demonstrar a possibilidade utilização integrada entre as práticas de Grupo de Discussão e de Grupo Focal no que tange a utilização conjunta ou isolada dos métodos descritos e utilizados, acreditamos que após uma década de emergência no Brasil, ainda haja muito que discutir, explorar e praticar, principalmente no cenário do cotidiano organizacional e suas temáticas também originárias do campo da sociologia. Entretanto, este exercício de tentar criar e exercitar foi de grande aprendizagem para os autores, uma vez que se parte de um suposto formalismo que, no entanto, na prática não funciona como manual didático, sequência necessária e aí, eis que é exigida do pesquisador, a verdadeira versatilidade inerente à pesquisa qualitativa: criar, sistematizar, revisitar, reformular e discutir e cima de algo preexistente. A própria convivência de um dos autores deste artigo com mentores da Pesquisa Social Qualitativa em Madri, principalmente a observação in loco da prática de Conde, permite afirmar: "faça o que eu digo, mas não faço o que faço". Com 40 anos de experiência em GD e ASD, os autores das segunda e terceira geração, respectivamente, sistematizaram os métodos e agora inovam. Portanto, se o formalismo é o rumo inicial, a luz no fim do túnel metodológico, a arte de criar, o caminho do pensamento é que constituem em cada trabalho o que se chama de metodologia.

Neste contexto, nos emparelhamos nos últimos anos - não mais com a geração que criou e sistematizou (a quem sempre faremos menção), mas com a geração que está inovando, utilizando material imagético, etc. A nossa prática que aqui transpareceu foi a grande dificuldade de como prescreve Conde - realizar antes os Procedimentos Interpretativos (principalmente configurar conjecturas "perfeitas" e explicativas de determinado módulo do fenômeno) e só após configurar a tríade analítica. A prática vem nos 
impelindo a revisitar Conde, pois se torna muito difícil partir de um insght, "um chute" bem elaborado redigir uma hipótese explicativa do objeto. Em geral, no Módulo Interpretativo estamos utilizando Conjecturas Pré-Analíticas provisórias, livres do pesquisador que, somente após passarem pelo verdadeiro "rolo compressor" da "tríade analítica" emergem como "hipóteses" melhor configuradas, mais completas e explanatórias em relação a determinado objetivo do estudo.

A principal dificuldade na elaboração deste caso exemplar foi a necessidade de limitação a pinçar apenas uma das oito Conjecturas Pré-Analíticas iniciais que foram tecendo a trama do discurso em cada grupo; além disso, aqui - pode-se falar "na quase morte do sujeito no texto" - crítica que fazemos a outras abordagens como a Análise Crítica do Discurso. Isto ocorreu em virtude da necessidade de priorizar a unidade e o nível de análise. No interior do "discurso grupal" não há indivíduos, há sujeitos estruturais (representantes e vários status) de tal forma que, sendo o grupo a unidade mínima de análise não interessaria no espaço deste texto, identificar trechos de indivíduos. Assim, o leitor recebeu as etapas modulares de forma já interpretada e elaborada. Cabe alertar, que em um trabalho maior o discurso direto deve aparecer a fim de não cair em pseudoanálise ou em análise apenas exemplos externalistas nas quais o discurso é apenas o palco, o cenário de disputa de poder pelos participantes. Alertamos, portanto, que um dos principais diferenciais da ASD em relação às práticas somente internalistas do texto (exemplo: Análise Clássica do Conteúdo; e grande parte da Escola Francesa de AD) reside no prioncipiantefato de que a ASD também se destaca em relação às práticas exclusivamente externalistas preocupadas com disputas de poder e ideologia entre os participantes que não necessariamente falam. Faz-se muito importante assinalar aqui ser a ASD tanto internalista quanto externalista. Não há como chegar na interpretação social dos discursos, sem passar antes pelo texto e pelo contexto.

Outra dificuldade de praticar qualquer abordagem de Análise do Discurso em Administração ou em Estudos Organizacionais reside na carência de pesquisadores com alguma formação em áreas traspassadas pelo discurso e pela interpretação, tais como, psicologia, psicanálise, linguística, etc. Justamente por nos considerarmos Sociologia Aplicada, fomos impelidos a buscar adequação mais próxima com a forma como os sociólogos praticam a Análise do Discurso.

Acreditamos que a principal contribuição desta modalidade de artigo exemplificador - diferente de um estudo de caso tradicional - resida no fato de que, a partir do momento em que a base teórica passa a ser o método, e os resultados a visualização das etapas dos métodos - possamos ter um alcance maior no interesse do pesquisador 
principiante que estuda qualquer outro assunto de nossa área. Ler apenas ensaios teóricometodológicos densos torna-se por vezes, impenetrável ao iniciante (e não apenas) compreender como praticar e criar a sua maneira de praticar. $\mathrm{O}$ acúmulo de artigos desta tipologia aqui narrada pode cada vez mais vir a distanciar a área de pseudoanálises do discurso (por localização de elementos; por excesso de trechos discursivos; por análise circular de pensamento; por falsa generalização). No caso específico deste artigo, acreditamos ter-se tornado evidente também a distinção epistemológica entre Grupo de Foco (Grupo Focal) que se destina a uma análise neo-positivista como Análise categorial ou do Conteúdo, bem como a coerência metodológico-epistêmica entre a coleta de discursos sociais por meio de Grupo de Discussão e seu correlato - na gênese - em serem estes discursos analisados pela via da Análise Sociológica do Discurso.

\section{REFERÊNCIAS}

ALONSO, L. E. La mirada cualitativa en sociología. Madrid: Fundamentos, 1998.

ALONSO, L. E.; CALLEJO, J. El análisis del discurso: del postmodernismo a las razones prácticas. Revista Española de Investigaciones Sociológicas (REIS), v. 88, n. 1 p. 37-73, 1999.

BAUDRILLARD, J. A Sociedade de consumo. Lisboa: Edições 70, 2010.

BRITO, J. G. Consignas para el «despegue» de un grupo de discusión: un modelo de presentació. EMPIRIA. Revista de Metodologia de Ciencias Sociales, v. 1, n. 2, p. 153$166,1999$.

BRITO, J. G. Elementos no-técnicos para la conducción de un grupo de discusión. EMPIRIA. Revista de Metodologia de Ciencias Sociales, v. 1, n. 4, p. 121-143, 2001.

CÁCERES, M. D. El cuerpo deseado y el cuerpo vivido.La apropiación de los discursos mediáticos y la identidad de gênero. Cuadernos de Informacion y Comunicacion-CIC, v. 13, n. 1, p. 195-212, 2008.

CALLEJO, J. El grupo de discusión: introducción a una práctica de investigación. Barcelona: Ariel Practicum, 2001.

CALLEJO, J. Grupo de discusión: la apertura incoherente. Estudios de Sociolingüística, v. 3, n. 1, p. 91-110, 2002.

CANO, M. S.; RUBIO, J. L. M. Una propuesta de evaluación de la calidad universitaria desde la perspectiva del grupo de discusión. Circunstancia. v. 3, n. 8, p. 44-66, 2005.

CONDE, F. G. A. Los grupos triangulares como "espacios transicionales" para la producción 
discursiva: un estudio sobre la vivienda en Huelva. In: GORDO, A.; SERRANO, A. (Eds.). Estrategias y prácticas cualitativas de investigación social. Madrid: Pearson Prentice Hall, 2008. p. 155-188.

CONDE, F. G. A. Cuadernos metodológicos: análisis sociológico del sistema de discursos. Madrid: Centro de Investigaciones Sociológicas, 2009.

CRIADO, Enrique Martín. El grupo de discusión como situación social. Revista Española de Investigaciones Sociológicas (REIS), v. 79, n. 1, p. 81-112, 1997.

DE LUCAS, A.; ORTÍ, A. Génesis y desarrollo de la práctica de grupo de discusión: fundamentación metodológica de la investigación social cualitativa. Investigación y Marketing, v. 47, n. 9, p. 6-9, 1995.

GODOI, C. K. Perspectivas de Análise do Discurso: possibilidades abertas aos estudos organizacionais. In: GODOI, C. K.; BANDEIRA-DE-MELLO, R.; SILVA, A.B. (Orgs.) Pesquisa Qualitativa em Estudos Organizacionais: paradigmas, métodos e técnicas. São Paulo: Atlas, 2010.

GODOI, C. K.; COELHO, A. L. A. L.; SERRANO, A. P. Elementos epistemológicos e metodológicos da Análise Sociológica do Discurso: abrindo possibilidades para os Estudos Organizacionais. Organização \& Sociedade, v. 21, n. 70, p. 509-535, 2014.

GODOI, C. K. Grupo de discussão como prática de pesquisa em estudos organizacionais. Revista de Administração de Empresas (RAE), v. 55, n. 6, p. 632-644, 2015.

GODOI, C. K.; MASTELLA, A.S. A noção de sujeito da pós-modernidade e as suas implicações para a análise de discurso. Revista Alcance. v. 22, n. 1, p.5-32, 2016.

GORDO, A. J. Análisis del discurso: los jóvenes y las tecnologías sociales. In: GORDO, A.; SERRANO, A. (Eds.). Estrategias y prácticas cualitativas de investigación social. Madrid: Pearson Prentice Hall, 2008. p. 213-242.

IBÁÑEZ, J. Más allá de la sociología - el grupo de discusión: técnica y crítica. Madrid: Ed. Siglo XXI, 1979.

IBÁÑEZ, J. Perspectivas de la investigación social: el diseño en las tres perspectivas. In: GARCÍA, M.; IBÁÑEZ, J.; ALVIRA, F. (Orgs.). El análisis del realidad social: métodos y técnicas de investigación. Madrid: Alianza Editorial, 2010. p. 59-71.

LAPLANCHE, J.; PONTALIS, J. B. Vocabulário da psicanálise. 4. ed. São Paulo: Martins Fontes, 2001.

LIPOVETSKY, G. O Império do efêmero: a moda e seu destino nas sociedades modernas. São Paulo: Companhia das Letras, 1989.

LIPOVETSKY, G. Metamorfose da cultura liberal: ética, mídia e empresa. Porto Alegre: 
Sulina, 2004.

ORTÍ, A. La apertura y el enfoque cualitativo o estructural: la entrevista abierta semidirectiva y la discusión de grupo. In: GARCÍA, M.; IBÁÑEZ, J.; ALVIRA, F. (Comps.). El análisis de la realidad social: métodos y técnicas de investigación. Madrid: Alianza Universidad, 2010. p. 153-186.

ORTÍ, A. En el margen del centro: la formación de la perspectiva sociológica crítica de la generación de 1956. Revista Española de Sociología, v. 1, p. 119-163, 2001.

PEINADO, A. La investigación cualitativa en España: de la vida política al maltrato del sentido. Revista Española de Salud Pública, v. 76, n. 5, p. 381-393, 2002.

PEREDA, C.; PRADA, M. A.; ACTIS, W.; ORTÍ, M. Discursos de la población migrante en torno a su instalación en España. Centro de Investigaciones Sociologicas, Opiniones y Actitudes, n. 64, 2010.

RUIZ RUIZ, J. Análisis sociológico del discurso: métodos y lógicas. Forum Qualitative Sozialforschung/Forum. Qualitative Social Research, v. 10, n. 2, p. 1-32, 2009.

SENAN, G.B. Consumo y cambio social en España: evolución en el equipamiento doméstico (1983-2005). Revista Española de Investigaciones Sociológicas (REIS). v. 120, n. 1, p. 75$114,2007$. 